\title{
Analysis of waves observed by synthetic aperture radar across
}

\section{ocean fronts}

Weizeng Shao ${ }^{1,2,3^{*}}$, Xingwei Jiang ${ }^{1,3}$, Ferdinando Nunziata ${ }^{4}$, Armando Marino ${ }^{5}$, Zhehao Yang ${ }^{2}$, Youguang Zhang ${ }^{1,3}$, Valeria Corcione ${ }^{4}$

1 National Satellite Ocean Application Service, Beijing 100081, China

2 Marine Science and Technology College, Zhejiang Ocean University, Zhoushan 316000, China

${ }^{3}$ Key Laboratory of Space Ocean Remote Sensing and Application, Ministry of Natural Resources of the People's Republic of China, Beijing 100081, China

${ }^{4}$ Dipartimento di Ingegneria, Università degli Studi di Napoli Parthenope, 80133 Napoli, Italy

${ }^{5}$ Natural Sciences, University of Stirling, Stirling FK9 4LA, UK

* Correspondence to: Dr. Wei-zeng Shao, shaoweizeng@mail.tsinghua.edu.cn Resubmitted to Ocean Dynamics

August, 2020 
1 Abstract: In this study, synthetic aperture radar (SAR) imaging of waves across ocean 2 fronts was investigated using C-band Sentinel-1 VV-polarized SAR imagery collected over the Yangtze and the Zhujiang estuaries. The presence of ocean fronts in the study area was confirmed by collocated sea surface temperature (SST) data provided by the Advanced Very High Resolution Radiometer (AVHRR) and sea surface current information from the National Ocean Partnership Program (NOPP) based on the HYbrid Coordinate Ocean Model (HYCOM). The experimental results revealed that as the current speed increased, the cut-off wavelength $\left(\lambda_{c}\right)$ increased as well. The effect of the increasing azimuth cut-off wavelength, however, was relatively weak in terms of variations of the normalized radar cross-section (NRCS), i.e., it was within $2 \mathrm{~dB}$ for $\lambda_{c} \leq 60 \mathrm{~m}$. Hence, it was weaker than the NRCS variation related to SST. Larger NRCS variations (i.e., within $5 \mathrm{~dB}$ ) occurred for $\lambda_{c}$ values up to $120 \mathrm{~m}$. In addition, the experimental results also demonstrated that the parameterized first-guess spectrum method (PFSM) wave retrieval performance was affected by ocean fronts. In particular, overestimations occurred when ocean fronts were present and $\lambda_{c}$ was $<100 \mathrm{~m}$.

Keywords: wave; ocean front; synthetic aperture radar

\section{Introduction}

Ocean fronts are common marine phenomena characterized by distinctive features of sea surface currents and temperatures and always accompanied by eddies and upwelling. These phenomena include a frontal boundary region featuring strong horizontal and vertical velocity gradients. Ocean fronts are of great importance in marine ecosystems and global climate change (Sydeman et al., 2014) due to their associated heat and nutrient exchanges. Operational products derived from remotely sensed measurements, and in particular by optical sensors, have generally been used to monitor ocean front events (Fragiacomo and Parmiggiani, 2002; McClain et al., 1984). There are some disadvantages in relying exclusively on optical images, however. Images can be noisy, they are not available when there is cloud cover, and increased 
1 biological activity in upwelling regions can introduce problems (Sousa and Bricaud, 1992). Moreover, sea surface currents are undetectable in optical satellite imagery.

Synthetic aperture radars (SARs) are active microwave instruments that can acquire high-resolution images in all weather conditions and at night. In fact, SARs even allow observations of the sea surface under extreme weather conditions (Corcione et al., 2018a; Li, 2015; Ding et al., 2019). Satellites carrying SARs operating at the Cband $(5.3 \mathrm{GHz})$ include the ERS-1/2, ENVISAT-ASAR, RADARSAT-1/2 (R-1/2), Sentinel-1A/1B (S-1), and Gaofen-3 (GF-3). The SAR-sensed backscattered signal intensity is influenced by sea surface roughness corresponding to the distribution of sea surface Bragg-backscattering waves, which depend on various processes such as wind (Masuko et al., 1986), ocean waves (Alpers, 1981), sea surface currents (Nilsson and Tildesley, 1995), ocean fronts (Lyzenga, 1991), tides (Li et al., 2015; Goldstein et al., 1989), and internal waves (Alpers, 1985).

Since sea surface long waves, currents, and atmospheric circulation processes may modulate the Bragg wave spectrum (Kudryavtsev et al., 1996; Jonhannessen et al., 1996), they can be observed by SAR. Various mechanisms of ocean fronts together with upwelling and eddies sensed by SAR have been studied for the last few decades, including the modulation of current-induced divergence and convergence on the sea surface (Marmorino et al., 1994), marine-atmosphere boundary layer instability caused by sea surface temperature (SST) (Friehe et al., 1991), and changes in the viscosity properties of the surface layer generated by cold water temperatures (Clemente-Colon et al., 1999).

It is well known that the SAR wave mapping mechanism includes tilt modulation, hydrodynamic modulation (Alpers et al., 1981), and nonlinear velocity bunching (Alpers and Bruning, 1986). Theoretical scattering physics is implemented in wave retrieval algorithms, e.g., the Max-Planck Institute (MPI) algorithm (Hasselmann and Hasselmann, 1991; Hasselmann et al., 1996), the semi-parametric retrieval algorithm (SPRA) (Mastenbroek and Valk, 2000), the parameterized first-guess spectrum method (PFSM) (Shao et al., 2015; Lin et al., 2017), and the partition rescaling and shift 
1 algorithm (PARSA) (Schulz-Stellenfleth et al., 2005; Li et al., 2010). Since ocean fronts affect SAR imaging of the sea surface, they play a key role when sea surface parameters are retrieved using SAR. In Li et al. (2009), it was demonstrated that ocean fronts associated with coastal upwelling modulate sea roughness, thus reducing the accuracy of wind retrieval algorithms. In particular, ocean fronts are mainly generated by changes in atmospheric stability due to air-sea temperature differences and sea surface currents (Kim et al., 2014). Under these circumstances, SAR wind retrieval using geophysical model functions is distorted (Xu et al., 2018; Hersbach et al., 2007; Hersbach, 2010). Theoretically, the wave field itself is affected by ocean fronts due to the curl of sea surface currents. Therefore, in this study, we examined the characteristics of SAR images when waves crossed the ocean front and rigorously validated the wave retrieval algorithm.

The remainder of the manuscript is organized as follows. Section 2 introduces the available datasets, including the S-1 SAR images, wind data from the European Centre for Medium-Range Weather Forecasts (ECMWF), sea surface current data from the National Ocean Partnership Program (NOPP) based on the HYbrid Coordinate Ocean Model (HYCOM), and SSTs from AVHRRs onboard National Oceanic and Atmospheric Administration (NOAA) satellites. The wave fields were simulated by a third-generation wave model-Simulating WAves Nearshore (SWAN). Section 3 describes the dependence of dynamic parameters on the main SAR-measured parameters, e.g., the normalized radar cross-section (NRCS) and azimuthal cut-off wavelength, in ocean front-dominated regions, and Section 4 presents a discussion of the results. Finally, Section 5 summarizes the conclusions of this study.

\section{Data sources}

The SAR dataset consisted of 28 C-band vertical-vertical (VV)-polarized interferometric wide-swath (IW) S-1 SAR images collected over the Yangtze Estuary or Zhujiang Estuary, China, where ocean fronts often occur. The pixel size was $5 \mathrm{~m} \times$ 
$120 \mathrm{~m}$ in the cross-track/along-track directions, respectively. The spatial coverage of the

2 S-1 SAR dataset is depicted in Figure 1, in which the spatial coverage of each S-1 image

3 is overlaid on the water depth (Figure 1). It should be noted that some S-1 SAR images

4 were acquired of the same geographic location at different times.

[Figure 1]

Two meaningful examples are showcased in Figure 2 comprising S-1 VVpolarized SAR images collected on (a) August 27, 2018 at 13:37 UTC in the South China Sea towards the Zhujiang Estuary and (b) June 15, 2016 at 11:50 UTC at the mouth of the Yangtze Estuary. In both cases, the alternating higher/lower backscattering was associated with ocean fronts that either dampened or enhanced sea surface roughness (Gurova et al., 2013). Other phenomena, however, such as light winds and natural/man-made slicks, may also affect sea surface roughness, making it difficult to discriminate these occurrences from ocean fronts. Therefore, AVHRR SST data were used to confirm the presence of ocean front regions. AVHRR SST maps related to the two S-1 images are presented in Figure 3, in which Figure 3(a) shows the SST map of the South China Sea on August 27, 2018 at 12:30 UTC and 3(b) shows the SST map around the Zhoushan Islands on June 15, 2016 at 10:30 UTC. Although there are time gaps of about two hours between the S-1 SAR image in the proximity the Zhoushan Islands and the AVHRR data, the pattern of low SSTs was generally consistent with the black regions in the S-1 SAR image. Contrary to this, the black regions in the S-1 SAR image of the South China Sea corresponded to the high SSTs. Although the dark patterns in the SAR images could be interpreted as upwelling, low SSTs can also be caused by other ocean phenomena, e.g., ocean fronts and cold eddies.

[Figure 2]

[Figure 3]

We also used the NOPP open-access sea surface current data simulated by the HYbrid Coordinate Ocean Model (HYCOM) on a spatial grid of $0.125^{\circ} \times 0.125^{\circ}$ at intervals of 3 hours each day, i.e., a well-developed ocean model for regional and global 
1 current analysis (Kelly et al., 2007; Kara and Barron, 2007). The sea surface current maps corresponding to the two cases are illustrated in Figure 4, in which the black rectangles represent the spatial coverage of the two SAR images. It was found that the current directions were not significantly changed in the S-1 SAR image of the South China Sea; hence, this occurrence was verified to be an ocean front. The dark pattern in the S-1 SAR image around the Zhoushan Islands, however, was most likely a cold eddy, given the spiral current direction.

[Figure 4]

The third-generation numerical wave model, referred to as the SWAN model (Siadatmousavi, 2011), has already been proven to allow the simulation of ocean waves in typhoons (Ou et al., 2002; Feng et al., 2011) in the China Sea (Liang et al., 2016; Han et al., 2017; Wang et al., 2018). The ECMWF wind data on a $0.125^{\circ}$ grid were taken as the forcing wind field, together with bathymetric data provided by the ETOPO1 dataset. The spatial resolution and time interval of the outputs, including currents and SSTs, were $0.05^{\circ}(\sim 5.5 \mathrm{~km})$ and $30 \mathrm{~min}$, respectively. The simulation process included the effects of currents on ocean waves. Since there are no available open-access moored buoys in the China Sea, Jason-2 altimeter measurements were used as a reliable data source in order to validate the simulation results from the SWAN model. The simulated significant wave height (SWH) maps of the South China Sea and the East China Sea are shown in Figure 5, in which the colored rectangles represent the footprints of the Jason-2 altimeter. The SWAN-simulated results are contrasted with the Jason-2 altimeter measurements in Figure 6, showing a 0.43-m root mean square error (RMSE). It must be noted that the region selected for comparison purposes was enclosed within the area ranging from $20^{\circ} \mathrm{S}$ to $38^{\circ} \mathrm{N}$ and $110^{\circ}$ to $140^{\circ} \mathrm{E}$. Hence, the RMSE resulting from the comparison was sufficiently accurate to allow us to use the SWAN simulations. 


\section{Methods and Results}

Velocity bunching was the main wave formation mechanism on the SAR image plane. Because there were strong marine phenomena existing in the collected SAR images, the azimuthal cut-off wavelengths derived from the SAR intensity were distorted to some extent. In this section, we first present the method for calculating the wavelength of the azimuthal cut-off on a SAR image, based on the simulated twodimensional wave spectra from the SWAN model. The azimuthal cut-off wavelength and dynamic ocean parameters, e.g., ECMWF wind speed, AVHRR SST, and NOPPHYCOM current speed, are then discussed for ocean front observation purposes.

\subsection{Derivation of azimuthal cut-off wavelength from SAR}

In this study, the two-dimensional spectrum simulated by the SWAN model was used to calculate the cut-off wavelength along the azimuthal direction (Stopa et al., 2015):

$$
\left\langle u_{0}^{2}\right\rangle=\left\langle w^{2}\right\rangle \cos ^{2} \beta+\left(\left\langle u^{2}\right\rangle \cos ^{2} \alpha+\left\langle v^{2}\right\rangle \sin ^{2} \alpha-2\langle u v\rangle \cos \alpha \sin \alpha\right) \sin ^{2} \beta,
$$

where $\alpha$ is the incidence angle; $\beta$ is the azimuth angle; $u, v$, and $w$ denote the eastwest, north-south, and vertical directions of the wave orbital velocities, respectively; and $\left\langle u_{0}^{2}\right\rangle$ is the variance of the wave velocity. In addition,

$$
\left\langle u^{2}\right\rangle=\int_{0}^{\infty} E(f, \theta)(2 \pi f)^{2} \cos ^{2} \theta d f d \theta
$$

$$
\left\langle v^{2}\right\rangle=\int_{0}^{\infty} E(f, \theta)(2 \pi f)^{2} \cos ^{2} \theta d f d \theta
$$

$$
\left\langle w^{2}\right\rangle=\int_{0}^{\infty} E(f, \theta)(2 \pi f)^{2} d f d \theta,
$$

$$
\langle u v\rangle=\int_{0}^{\infty} E(f, \theta)(2 \pi f)^{2} \cos \theta \sin \theta d f d \theta,
$$

in which $E(f, \theta)$ is the two-dimensional wave spectrum; $f$ is the wave frequency; and $\theta$ is the wave propagation direction. The cut-off wavelength in the azimuthal direction, $\lambda_{c}$, is then expressed as 


$$
\lambda_{c}=\pi \frac{R}{V} \sqrt{\left\langle u_{0}\right\rangle^{2}}
$$

where $R / V$ is the ratio coefficient between slant distance and platform velocity. As an example, the azimuthal cut-off wavelength estimate using the simulated twodimensional wave spectrum from the SWAN model is shown in Figure 7.

\section{[Figure 7]}

\subsection{Analysis results}

The processing consisted of partitioning each SAR image into $32 \times 32$ subscenes along the range and azimuth directions, respectively. Auxiliary data (ECMWF wind vectors, NOPP-HYCOM current speeds, and AVHRR SSTs) were then used to generate waves from 13,000 matchups. The ECMWF wind speed at a height of $10 \mathrm{~m}$ above the sea surface was contrasted with the SAR-measured NRCS (Figure 8a) and the azimuth cut-off (Figure 8b). It has generally been found that wind speed has an exponential relationship with NRCS (Masuko et al., 1986), which allowed the development of the geophysical model function (GMF) for SAR wind retrieval (Stoffelen and Anderson, 1997), although a complex sea state characterized these SAR images. In recent research, the performance of C-band model (CMOD) wind retrieval was investigated under such conditions, revealing that ocean fronts cause an underestimation of retrieved wind speed with respect to reference buoy measurements (Xu et al., 2018). The azimuthal cut-off wavelength should have a linear relationship with wind speed in the fully developed sea state (Corcione et al., 2018b). In this study, the azimuthal cut-off wavelength exhibited a similar relationship for wind speeds $>8$ $\mathrm{m} / \mathrm{s}$ (Figure $8 \mathrm{~b}$ ), although a decreasing trend was observed for wind speeds from 4 to 8 $\mathrm{m} / \mathrm{s}$.

[Figure 8]

The NOPP-HYCOM sea surface current speed data were contrasted with the SARmeasured NRCS and the azimuthal cut-off wavelength for current speeds ranging from 0 to $0.45 \mathrm{~m} / \mathrm{s}$, as presented in Figure 9. The NRCS was found to decrease with 
1 increasing current speed, and the maximum change of NRCS was within $2 \mathrm{~dB}$. This is 2 because the NRCS is positively correlated with wind-induced waves, while currents in

3 the horizontal direction are not closely related to wave variations. In the presence of a 4 current, the current-wave interaction may promote the wave energy. On the other hand, 5 the azimuthal cut-off wavelength $\lambda_{c}$ is explicitly related to the SWH (Shao et al., 6 2016). This explains the increase of the azimuthal cut-off wavelength with increasing

current speed, although the change of the azimuthal cut-off wavelength was approximately $60 \mathrm{~m}$. The AVHRR SST is contrasted with the S-1 NRCS and azimuthal cut-off wavelength $\lambda_{c}$ in Figure 10. Figure 10(a) shows the cosine-type behavior of the NRCS with SST. The relationship between SST and $\lambda_{c}$ also exhibited this type of behavior, as shown in Figure 10(b). The wind-sea interaction layer can be affected by SST in ocean front regions, causing the change of NRCS to reach $5 \mathrm{~dB}$ and the azimuthal cut-off wavelength induced by SST to exceed $120 \mathrm{~m}$. Therefore, SST variability was found to be the main force modulating the Bragg waves.

\section{[Figure 9]}

[Figure 10]

\section{Discussion}

In this section, the SAR-derived wave spectra crossing the ocean front in Figure 1 is analyzed. The PFSM algorithm (Lin et al., 2017) was used to retrieve the wave spectra following the red rectangles in Figures 2(a) and (b). Wind speed data are required in order to apply the PFSM. In this study, however, since the SAR-derived wind speeds deviated significantly from the actual wind speeds, the ECMWF wind speeds on a 0.125 grid were employed. To obtain reliable wind speeds, a bilinear interpolation was adopted for both the spatial and the temporal scales. The two ECMWF wind speed maps from the ECMWF are presented in Figure 11, in which the black rectangles represent the spatial coverage of the two S-1 SAR images. 
In Figures 12 and 13, the curves represent the normalized SAR-derived wave spectra of sample lines crossing the dark regions in the two cases. The maximum frequency was lowered to $1 \mathrm{~s}$ and the gaps that appeared in the SAR-derived wave spectra (at wavelengths $>100 \mathrm{~m}$ ) were due to velocity bunching. The case shown in Figure 12 deals with the SAR image located in the South China Sea in which the azimuthal cut-off wavelength increases from $\mathrm{A}$ to $\mathrm{H}$. The dark regions from $\mathrm{A}$ to $\mathrm{C}$ correspond to high SSTs, although the current directions significantly changed and the current speeds in Figure 4 are $>0.2 \mathrm{~m} / \mathrm{s}$. The SAR-derived wave spectra were overestimated with respect to the SWAN-simulated wave spectra, in which the short waves with wavelengths $<100 \mathrm{~m}$ dominated. In the ocean front regions ( $\mathrm{D}$ to $\mathrm{H}$ ), the SAR-derived wave spectra were close to the SWAN-simulated wave spectra at wavelengths $>130 \mathrm{~m}$. As for the case located in the East China Sea, two small cold eddies (A to D, H, and G) occurred on the sides of the ocean front, as seen in Figures $3 \mathrm{~b}$ and $4 \mathrm{~b}$. It should be noted that, even in this case, the SAR-derived wave spectra exhibited large deviations with respect to the SWAN-simulated spectra. The PFSM algorithm performed better without the distortion caused by the ocean front, where the azimuthal cut-off wavelength was $>100 \mathrm{~m}$.

[Figure 12]

[Figure 13]

\section{Conclusions}

Ocean fronts, together with upwelling and eddies, are interesting topics for the marine science community, particularly the occurrence of fronts in relation to other dynamic processes, such as sea surface winds, currents, and SSTs. The SAR is a unique remote sensing tool that can observe the sea surface over a large spatial area. In this study, several C-band S-1 VV-polarized SAR images located in the Yangtze Estuary and Zhujiang Estuary, China were acquired during the period spanning 2017-2018. The ECMWF wind speed data, AVHRR SST data, and NOPP-HYCOM current fields were 
1 simultaneously used. The wave fields, including SWH and two-dimensional wave

2 spectra, were simulated using the SWAN model collocated with the S-1 SAR images.

3 The simulated SWHs were also verified against Jason-2 altimeter measurements.

The NOPP-HYCOM currents were used to verify the ocean fronts, and AVHRR SST data were employed to verify the occurrence of upwelling or cold eddies. It was discovered that in the East China Sea case (around the Zhoushan Islands), the dark patterns that appeared in the SAR images corresponded to low SST regions, while the black regions for the case in the South China Sea were related to high SST regions. The azimuthal cut-off wavelength was found to decrease with wind speed up to $8 \mathrm{~m} / \mathrm{s}$, above which it increased with increasing wind speed. In addition, the azimuthal cut-off wavelength increased with increasing current speed. The changes in the azimuthal cutoff wavelength induced by the current were $\leq 60 \mathrm{~m}$, while the changes induced by the SST were more pronounced $(>120 \mathrm{~m})$. We conclude that SST mainly contributes to the change in sea surface roughness, while current is likely to be a significant factor driving the change of the azimuthal cut-off wavelength. In the presence of ocean fronts, the PSFM algorithm overestimates wave retrieval compared to the SWAN simulation.

In the near future, we plan to collect more SAR images covering the ocean front region and attempt to develop an algorithm for wave retrieval taking into account the influence of SST. Furthermore, the linear relationship between current and azimuthal cut-off wavelength can be utilized for current speed retrieval from SAR images.

\section{Acknowledgments}

We appreciate the freely accessible Sentinel-1 SAR images provided by the European Space Agency (ESA) at https://scihub.copernicus.eu. The wind and wave data from the European Centre for Medium-Range Weather Forecasts (ECMWF) were accessed via http://www.ecmwf.int. Ocean current field data from from the National Ocean Partnership Program (NOPP) based on the HYbrid Coordinate Ocean Model (HYCOM) were collected from https://www.hycom.org. Operational Geophysical Data 
1 Record (OGDR) wave data from the Jason-2 altimeter mission were accessed via 2 https://data.nodc.noaa.gov. Data from the General Bathymetric Chart of the Oceans

3 (GEBCO) were downloaded from ftp.edcftp.cr.usgs.gov. This work was partly 4 supported by the National Key Research and Development Program of China under contract No. 2017YFA0604901, the National Natural Science Foundation of China under contract Nos. 41806005 and 41776183, the China Postdoctoral Science Foundation under contract No. 2020M670245, and the Science and Technology Project of Zhoushan City under contract No. 2019C21008.

\section{References:}

Alpers W, Ross D B, Rufenach C L. 1981. On the Detectability of Ocean Surface Waves by Real and Synthetic Radar. Journal of Geophysical Research, 86 (C4): 1052910546, doi: 10.1029/jc086ic07p06481.

Alpers W. 1985. Theory of Radar Imaging of Internal Waves. Nature, 314 (6008): 245247, doi: $10.1038 / 314245 \mathrm{a} 0$.

Alpers W, Bruning C. 1986. On the Relative Importance of Motion-related Contributions to the SAR Imaging Mechanism of Ocean Surface Waves. IEEE Transactions on Geosciences and Remote Sensing, GE-24 (6): 873-885, doi: 10.1109/joe.1982.1145517.

Clemente-Colon P, Yan X H. 1999. Observations of East Coast Upwelling Conditions in Synthetic Aperture Radar Imagery. IEEE Transactions on Geoscience and Remote Sensing, 37 (5): 2239-2248, doi: 10.1109/36.789620.

Corcione V, Nunziata F, Migliaccio M, 2018a. Megi Typhoon Monitoring by X-Band Synthetic Aperture Radar Measurements. Journal of Oceanic Engineering, 43 (1): 184-194, doi: 10.1109/JOE.2017.2700558.

Corcione V, Grieco G, Portabella M, Nunziata F, Migliaccio M. 2018b. A Novel Zzimuth Cut-off Implementation to Retrieve Sea Surface Wind Speed from SAR 
Imagery. IEEE Transactions on Geoscience and Remote Sensing, 57 (6): 33313340, doi: 10.1109/TGRS.2018.2883364.

Ding Y Y, Zuo J C, Shao W Z, Shi J, Yuan X Z, Sun J, Hu J C, Li X F. 2019. Wave Parameters Retrieval for Dual-polarization C-band Synthetic Aperture Radar using a Theoretical-based Algorithm under Cyclonic Conditions. Acta Oceanologica Sinica, 38 (5): 21-31, doi: 10.1007/s13131-019-1438-y.

Egbert G D, Erofeeva S Y. 2002. Efficient inverse Modeling of barotropic ocean tides. Journal of Atmospheric and Oceanic Technology, 19(2): 183-204, doi: 10.1175/1520-0426(2002)019<0183:EIMOBO >2.0.CO;2.

Friehe C A, Shaw W J, Rogers D P, Davidson K L, Large W G, Stage S A, Crescenti G H, Greenhut G K, Khalsa S J S, Li F. 1991. Air-sea Fluxes and Surface Layer Turbulence around a Sea Surface Temperature Front. Journal of Geophysical Research Oceans, 96 (C5): 8593-8609, doi: 10.1029/90JC02062.

Fragiacomo C, Parmiggiani F. 2002. An Upwelling Event in the Central Mediterranean Sea Detected by Quickscat and by AVHRR. International Journal of Remote Sensing, 23 (24): 5151-5153, doi: 10.1080/0143116021000016752.

Feng X, Yin B, Yang D, William P. 2011. The Effect of Wave-induced Radiation Stress on Storm Surge during Typhoon Saomai (2006). Acta Oceanologica Sinica, 30 (3): 20-26, doi: 10.1007/s13131-011-0115-6.

Goldstein R M, Zebker, H A, Barnett T P. 1989 Remote Sensing of Ocean Currents. Science, 246(4935): 1282-1285, doi: 10.1126/science.246.4935.1282.

Gurova E, Lehmann A, Ivanov A. 2013. Upwelling Dynamics in the Baltic Sea Studied by a Combined SAR/Infrared Satellite Data and Circulation Model Analysis. Oceanologia, 55 (3): 687-707, doi: 10.5697/oc.55-3.687.

Hasselmann K, Hasselmann S. 1991. On the Nonlinear Mapping of an Ocean Wave Spectrum into a Synthetic Aperture Radar Image Spectrum. Journal of Geophysical Research, 96 (C6): 10713-10729, doi: 10.1029/91jc00302. 
1 Hasselmann S, Bruning C, Hasselmann K. 1996. An Improved Algorithm for the

Hersbach H, Stoffelen A, Haan S D. 2007. An Improved C-band Scatterometer Ocean Geophysical Model Function: CMOD5. Journal of Geophysical Research: Oceans, 112 (C3), doi: 10.1029/2006JC003743.

Hersbach H. 2010. Comparison of C-band Scatterometer CMOD5.N Equivalent Neutral Winds with ECMWF. Journal of Atmospheric and Oceanic Technology, 27 (4): 721-736, doi: 10.1175/2009JTECHO698.1.

Han S Z, Fan, Y B, Dong Y Y, Wu S Q. 2017. A Study on the Relationships Between the Wave Height and the El Niño in the North Area of the South China Sea. Acta Oceanologica Sinica, 36(5), 44-50, doi: 10.1007/s13131-017-1059-2.

Johannessen J A, Shuchman R A, Digranes G. , Lyzenga D R, Wackerman C, Johannessen O M, Vachon P V. 1996. Coastal Ocean Fronts and Eddies Imaged with ERS-1 Synthetic Aperture Radar. Journal of Geophysical Research, 101 (C3): 6651, doi: 10.1029/95jc02962.

Kelly K A, Thompson L A, Cheng W, Metzger E J. 2007. Evaluation of HYCOM in the Kuroshio Extension Region Using New Metrics. Journal of Geophysical Research: Oceans, 112 (C1): C01004, doi: 10.1029/2006JC003614.

Kara A B, Barron C N. 2007. Fine-resolution Satellite-based Daily Sea Surface Temperatures over the Global Ocean. Journal of Geophysical Research: Oceans, 112 (C5): C05041, doi: 10.1029/2006jc004021.

Kudryavtsev V N, Grodsky S A, Dulov V A, Malinovsky V V. 1996. Observations of Atmospheric Boundary Layer Evolution above the Gulf Stream Frontal Zone. Boundary-Layer Meteorology ,79 (1): 51-82, doi: 10.1007/BF00120075.

Kim T S, Park K A, Li X, Hong S. 2014. SAR-derived Wind Fields at the Coastal Region in the East/Japan Sea and Relation to Coastal Upwelling. International 
Journal of Remote Sensing, 35 (11-12): 3947-3965, doi: $10.1080 / 01431161.2014 .916438$.

Lyzenga D R. 1991. Interaction of short surface and electromagnetic waves with ocean fronts. Journal of Geophysical Research, 96 (C6): 10765, doi: 10.1029/91jc00900.

Li X M, Li X F, He M X. 2009. Coastal Upwelling Observed by Multi-satellite Sensors. Science in China Series D: Earth Sciences, 52 (7): 1030-1038, doi: 10.1007/s11430-009-0088-X.

Li X M, Konig T, Schulz-Stellenfleth J, Lehner S. 2010. Validation and Intercomparison of Ocean Wave Spectra Inversion Schemes Using ASAR Wave Mode Data. International Journal of Remote Sensing, 31 (17): 4969-4993, doi: $10.1080 / 01431161.2010 .485222$.

Li X M, Chi L, Chen X, Ren Y Z, Lehner S. 2015. SAR Observation and Numerical Modeling of Tidal Current Wakes at the East China Sea Offshore Wind Farm. Journal of Geophysical Research Oceans, 119 (8): 4958-4971, doi: $10.1002 / 2014 \mathrm{jc} 009822$.

Liang B C, Liu X, Li H J, Wu Y J, Lee D Y. 2016. Wave Climate Hindcasts for the Bohai Sea, Yellow Sea, and East China Sea. Journal of Coastal Research, 32 (1): 172-180, doi: 10.2112/JCOASTRES-D-14-00017.1.

Lin B, Shao W Z, Li X F, Li H, Du X Q, Ji Q Y, Cai L N. 2017. Development and Validation of an Ocean Wave Retrieval Algorithm for VV-polarization Sentinel-1 SAR Data. Acta Oceanologica Sinica, 36 (7): 95-101, doi: 10.1007/s13131-0171089-9.

McClain C R, Pietrafesa L J, Yoder J A. 1984. Observations of Gulf Stream-induced and Wind-driven Upwelling in the Georgia Bight using Ocean Color and Infrared Imagery. Journal of Geophysical Research Oceans, 89 (C3): 3705-3723, doi: 10.1029/JC089iC03p03705. 
1 Masuko H, Okamoto K, Shimada M, Niwa S. 1986. Measurement of Microwave Backscattering Signatures of the Ocean Surface using X Band and Ka Band Airborne Scatterometers. Journal of Geophysical Research Oceans, 91 (C11): 13065-13083, doi: 10.1029/JC091iC11p13065.

Marmorino G O, Jansen R W, Valenzuela G R, Trump C L, Lee J S, Kaiser J A C. 1994. Gulf Stream Surface Convergence Imaged by Synthetic Aperture Radar. Journal of Geophysical Research Oceans ,99 (C9): 18315-18328, doi: 10.1029/94jc01643.

Mastenbroek C, Valk C F de. 2000. A Semi-parametric Algorithm to Retrieve Ocean Wave Spectra from Synthetic Aperture Radar. Journal of Geophysical Research, 105 (C2): 3497-3516, doi: 10.1029/1999jc900282.

Nilsson C S, Tildesley P C. 1995. Imaging of Oceanic Features by ERS-1 Synthetic Aperture Radar. Journal of Geophysical Research, 100 (C1): 953, doi: $10.1029 / 94 j \mathrm{jc} 02556$.

Ou S H, Liau J M, Hsu T W, Tzang S Y. 2002. Simulating Typhoon Waves by SWAN Wave Model in Coastal Waters of Taiwan. Ocean Engineering, 29 (8): 947-971, doi: 10.1016/S0029-8018(01)00049-X.

Stoffelen A, Anderson D. 1997. Scatterometer Data Interpretation: Estimation and Validation of the Transfer Function: CMOD4. Journal of Geophysical Research, 102 (C3): 5767 - 5780, doi: 10.1029/96JC02860.

Schulz-Stellenfleth J, Lehner S, Hoja D. 2005. A Parametric Scheme for the Retrieval of Two-dimensional Ocean Wave Spectra from Synthetic Aperture Radar Look Cross Spectra. Journal of Geophysical Research, 101 (C5): 297-314, doi: 10.1029/2004JC002822.

Siadatmousavi S M, Jose F, Stone G W. 2011, The Effects of Bed Friction on Wave Simulation: Implementation of an Unstructured Third-Generation Wave Model, SWAN. Journal of Coastal Research 27 (1): 140-152, doi: 10.2307/25790496. 
1 Sousa F M, Bricaud A. 1992. Satellite-derived Phytoplankton Pigment Structures in the

Sydeman W J, García-Reyes M, Schoeman D S, Rykaczewski R R, Thompson S A, Black B A, Bograd S. 2014. Climate Change and Wind Intensification in Coastal Upwelling Ecosystems. Science, 345 (6192): 77-80, doi: $10.1126 /$ science. 1251635 .

Shao W Z, Li X F, Sun J. 2015. Ocean Wave Parameters Retrieval from TerraSAR-X Images Validated Against Buoy Measurements and Model Results. Remote Sensing, 7 (10): 12815-12828, doi: 10.3390/rs71012815.

Stopa J E, Ardhuin F, Chapron B, Collard F. 2015. Estimating Wave Orbital Velocity through the Azimuth Cut-off from Space-borne Satellites. Journal of Geophysical Research,120 (11): 7616-7634, doi: 10.1002/2015JC011275.

Shao W Z, Zhang Z, Li X F, Li H. 2016. Ocean Wave Parameters Retrieval from Sentinel-1 SAR imagery. Remote Sensing, 8 (9), 707, doi: 10.3390/rs8090707.

Shao W Z, Hu Y Y, Zheng G, Cai L N, Zou J C. 2020. Sea State Parameters Retrieval from Ccross-polarization Gaofen-3 SAR Data. Advances in Space Research, 65(2020): 1025-1034, doi: 10.1016/j.asr.2019.10.034.

Xu Q, Li Y Z, Li X F, Zhang Z H, Cao Y N, Cheng Y C. 2018. Impact of Ships and Ocean Fronts on Coastal Sea Surface Wind Measurements from the Advanced Scatterometer. IEEE Journal of Selected Topics in Applied Earth Observations and Remote Sensing, 11 (7): 2162-2169, doi: 10.1109/JSTARS.2018.2817568.

Wang Y P, Mao X Y, Jiang W S. 2018. Long-term Hazard Analysis of Destructive Storm Surges using the ADCIRC-SWAN model: A Case Study of Bohai Sea, China. International Journal of Applied Earth Observation and Geoinformation, 73: 5262, doi: 10.1016/j.jag.2018.03.013. 


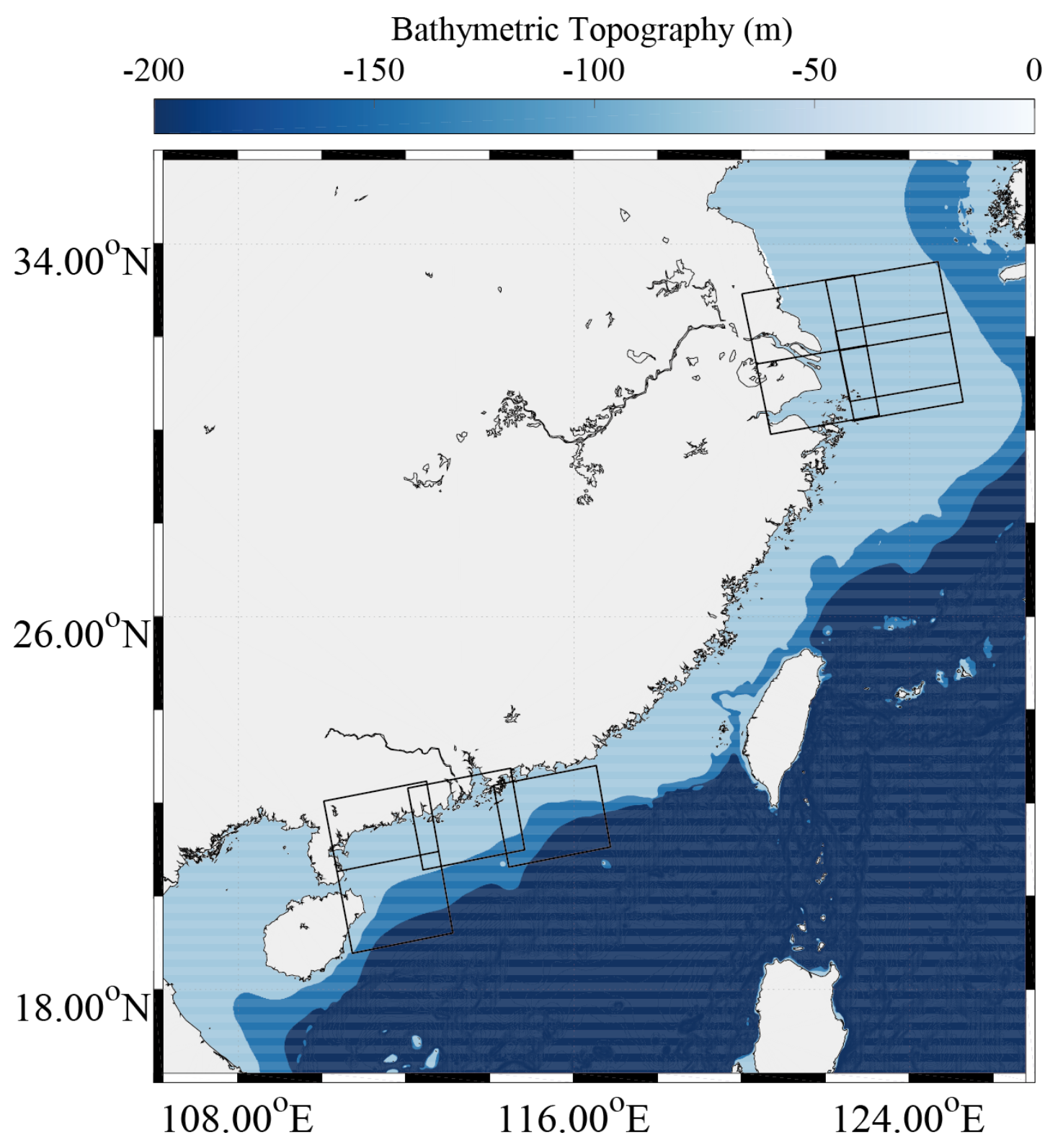

Fig. 1. S-1 SAR dataset overlaid on water depth

The rectangles represent the spatial coverage of the SAR imagery. 


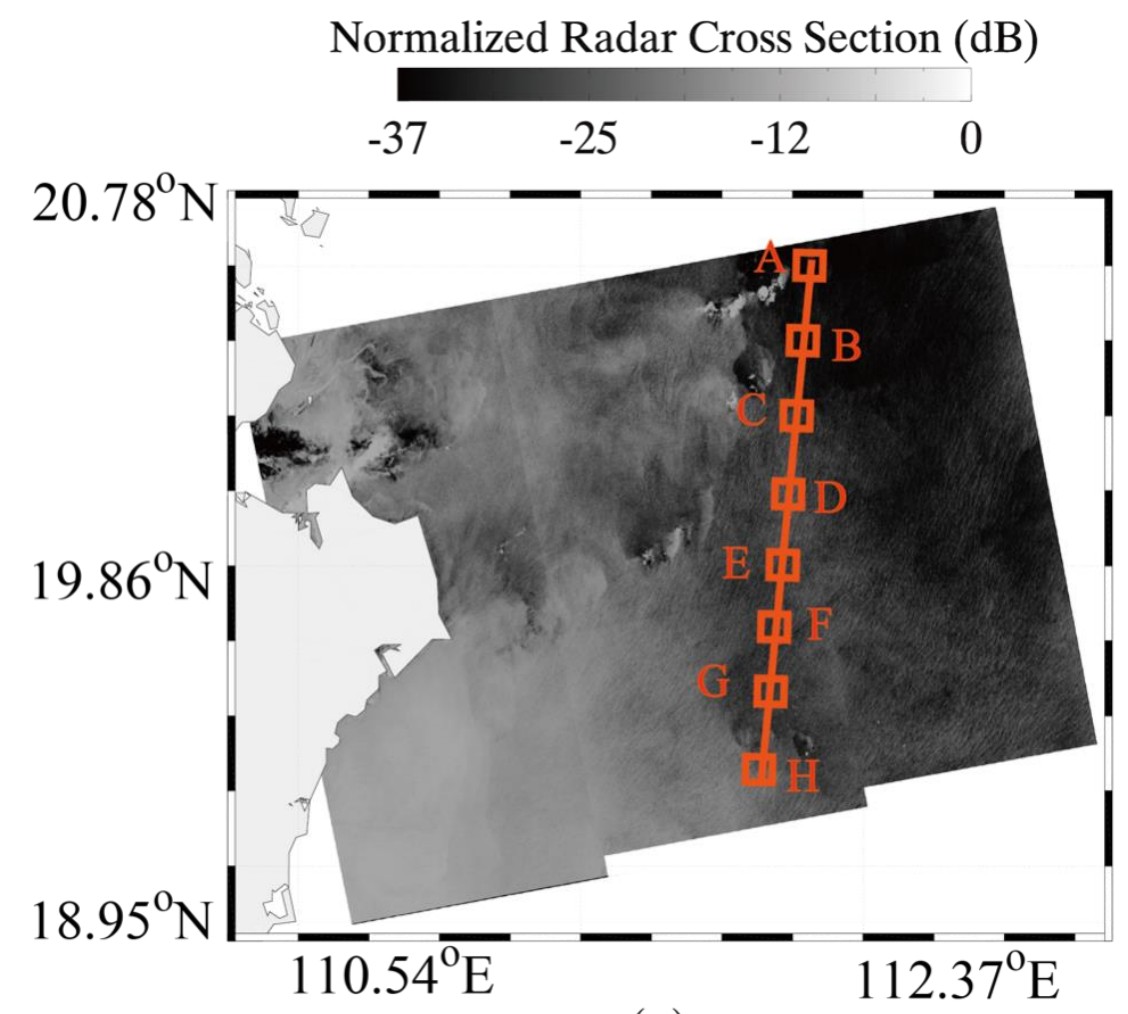

(a)

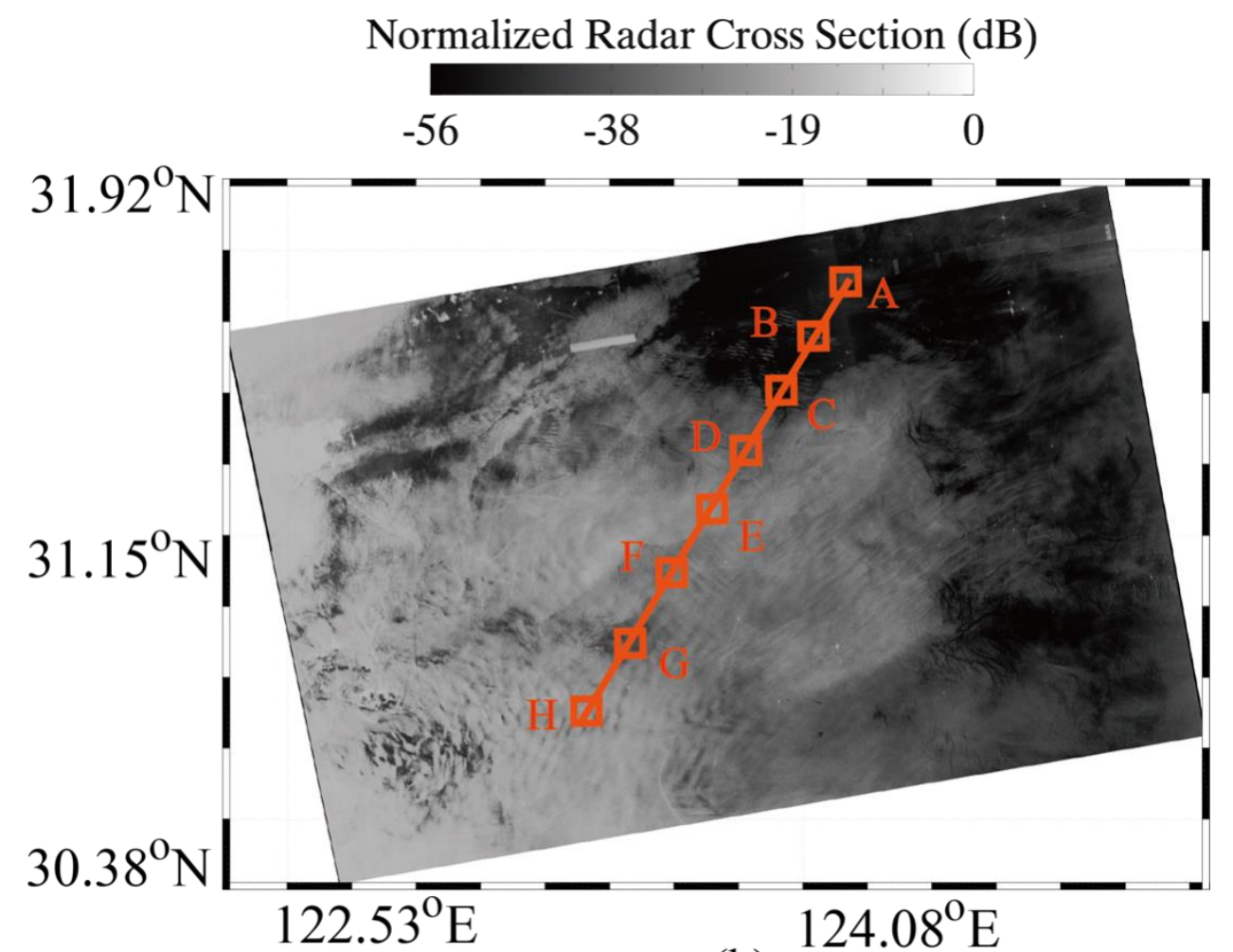

(b)

2 Fig. 2. S-1 VV-polarized and calibrated NRCS imagery showing ocean fronts collected 3 on: (a) August 27, 2018 at 13:37 UTC at the mouth of the Yangtze Estuary; (b) June 15, 2016 at 11:50 UTC in the South China Sea towards the Zhujiang Estuary

$5 \quad$ The red lines and rectangles are selected profiles across the ocean fronts. 
Sea Surface Temperature $\left({ }^{\circ} \mathrm{C}\right)$

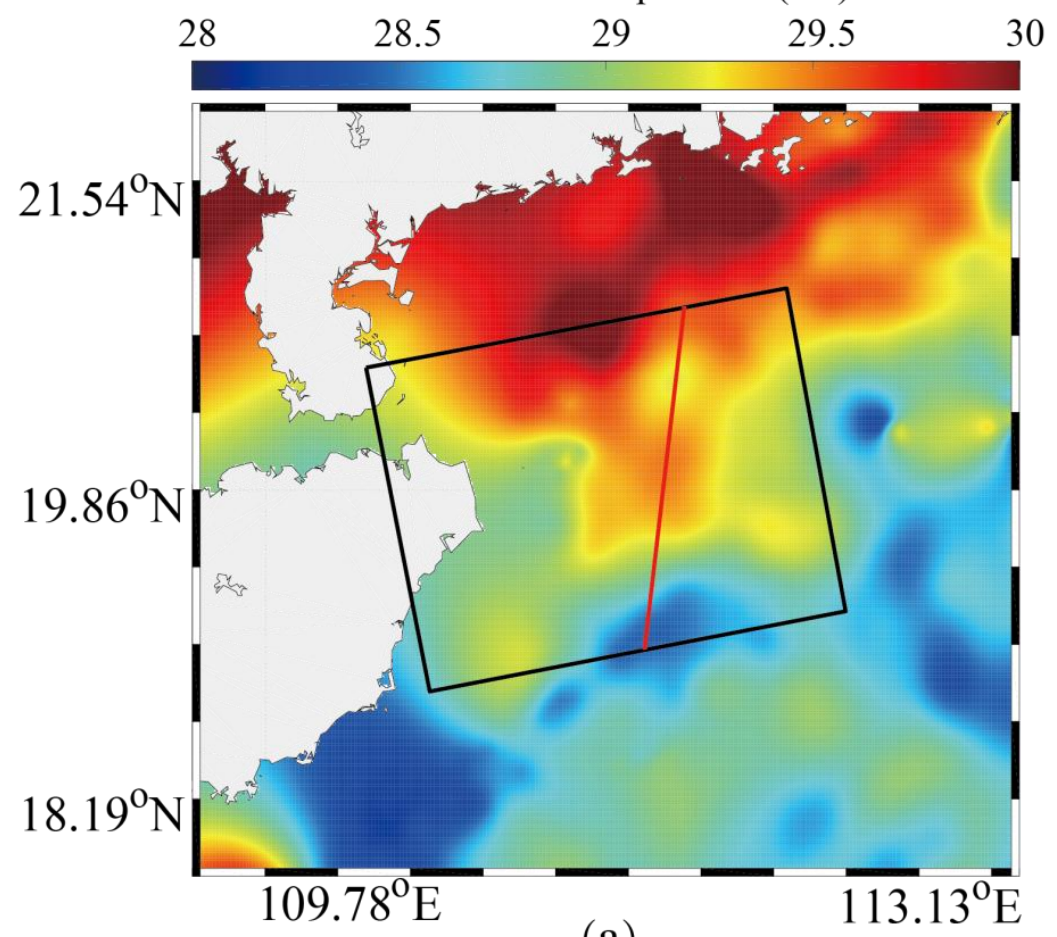

(a)

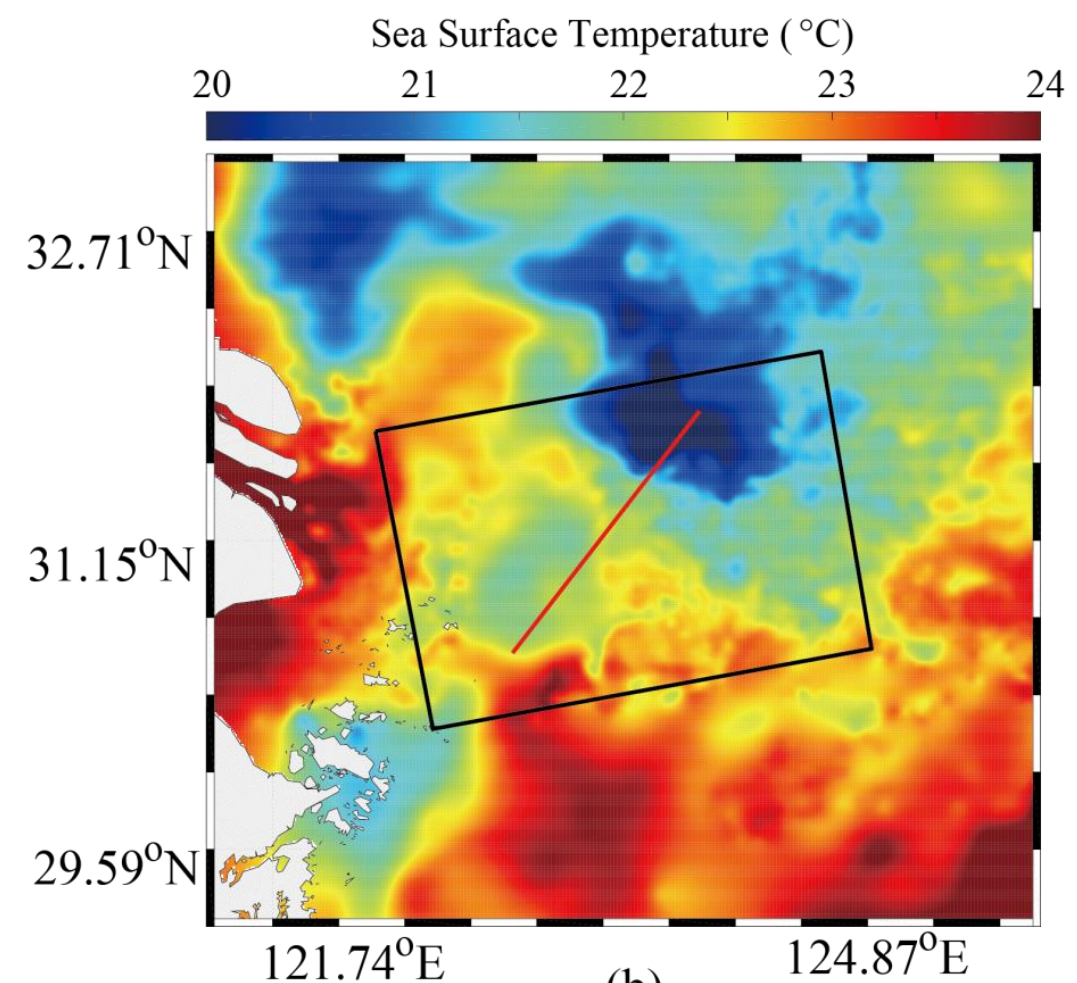

(b)

2 Fig. 3. AVHRR SST maps related to the acquisitions collected on: (a) August 27, 2018 at 12:30 UTC in the South China Sea; (b) June 15, 2016 at 10:30 UTC around the Zhoushan Islands

5 The black rectangles represent the spatial coverage of the two S-1 SAR images and the red lines are selected profiles across the ocean fronts. 


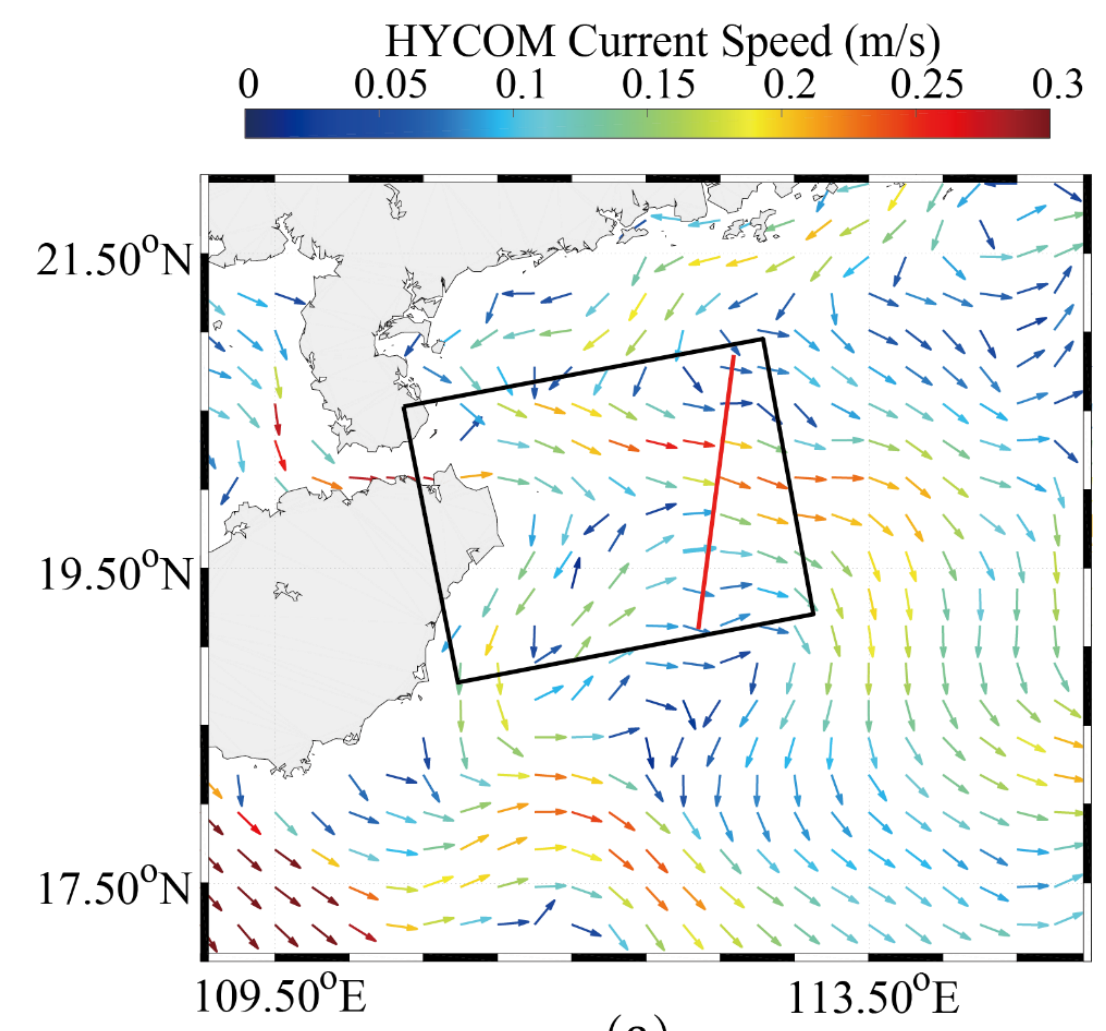

(a)

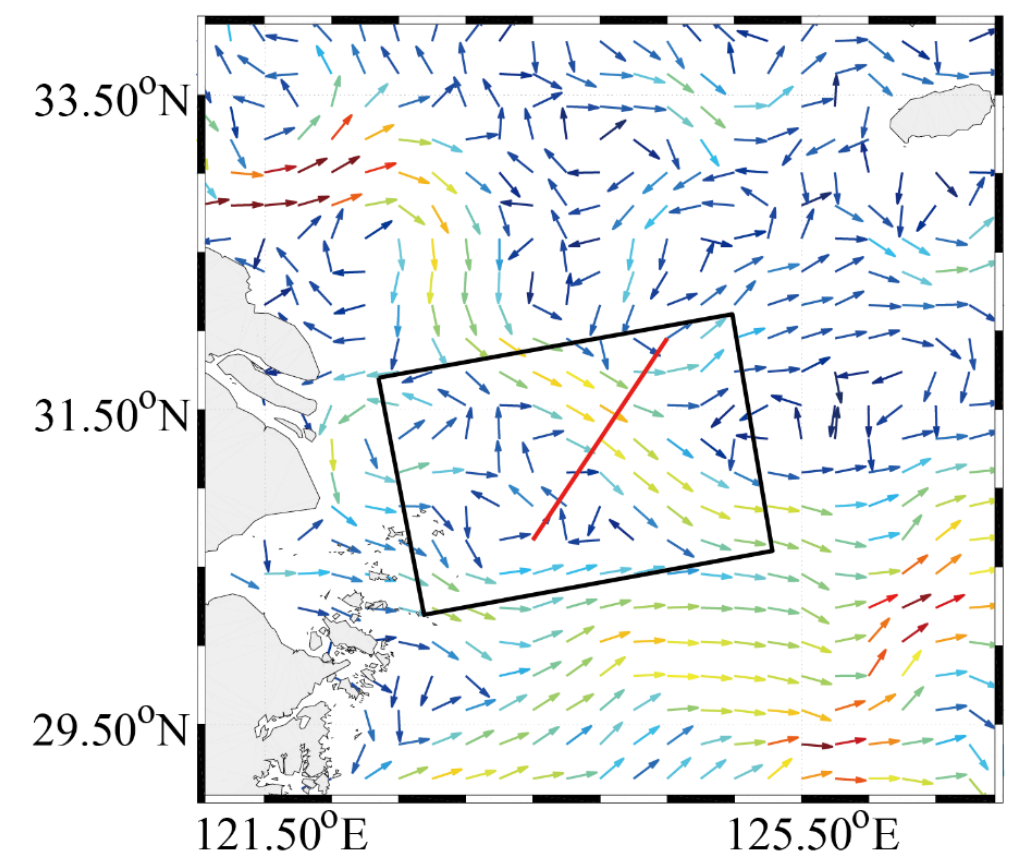

(b)

2 Fig. 4. Sea surface currents from the National Ocean Partnership Program (NOPP) based 3 on the HYbrid Coordinate Ocean Model (HYCOM), in which the black rectangles represent the spatial coverage of the two SAR images and the red lines and rectangles are selected profiles across the ocean fronts, in which (a) represents the current speed map on August 27, 2018 at 12:00 UTC in the South China Sea, and (b) represents the current speed map on June 15, 2016 at 12:00 UTC around the Zhoushan Islands. 


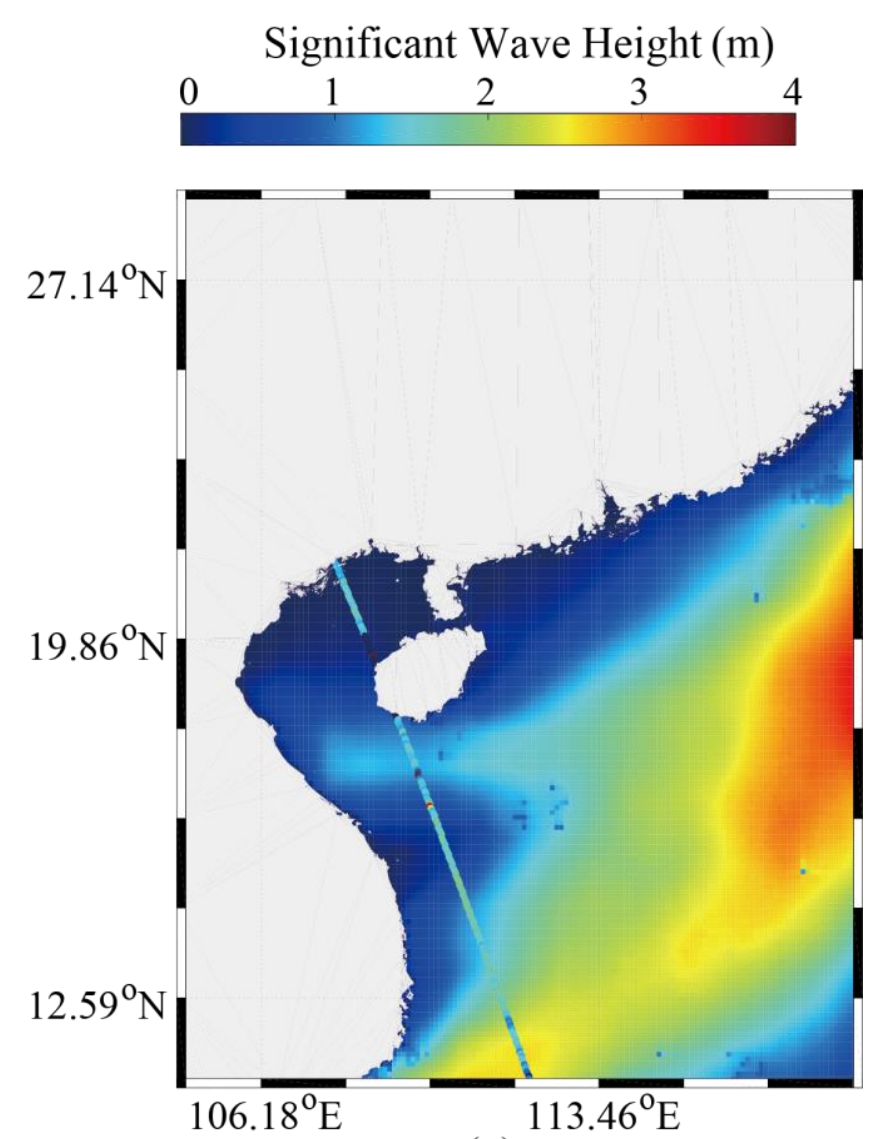

(a)

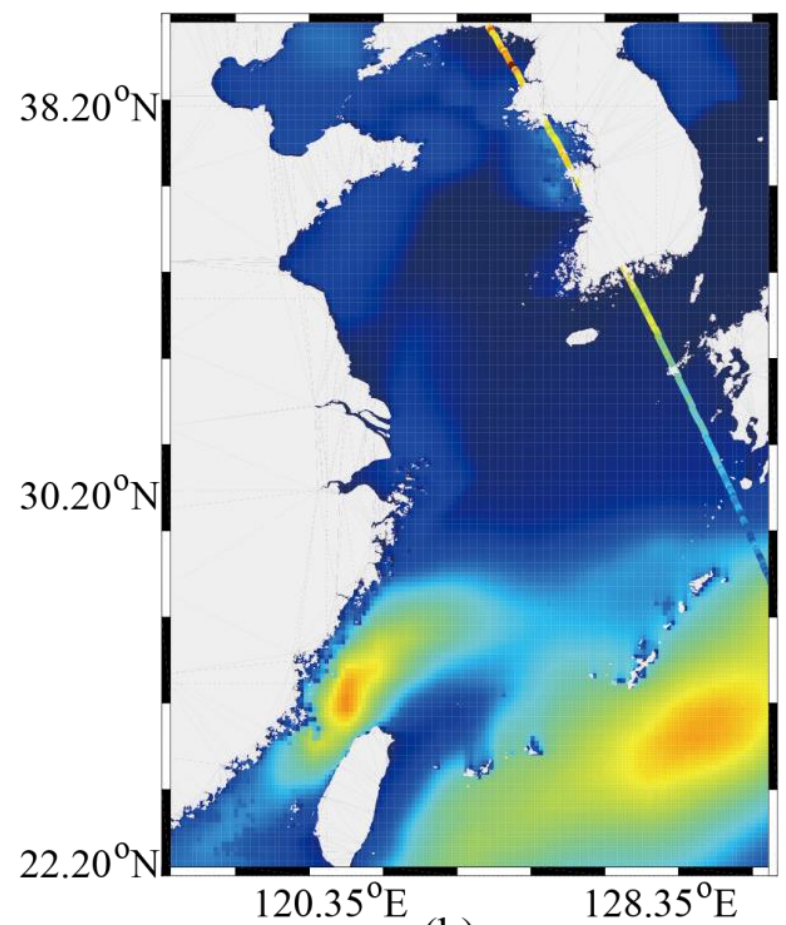

(b)

2

Fig. 5. Simulated significant wave height (SWH) maps using the Simulating WAves Nearshore (SWAN) model

The colored rectangles represent the footprints of the Jason-2 altimeter and the 

simulated regions refer to (a) the South China Sea and (b) the East China Sea. 


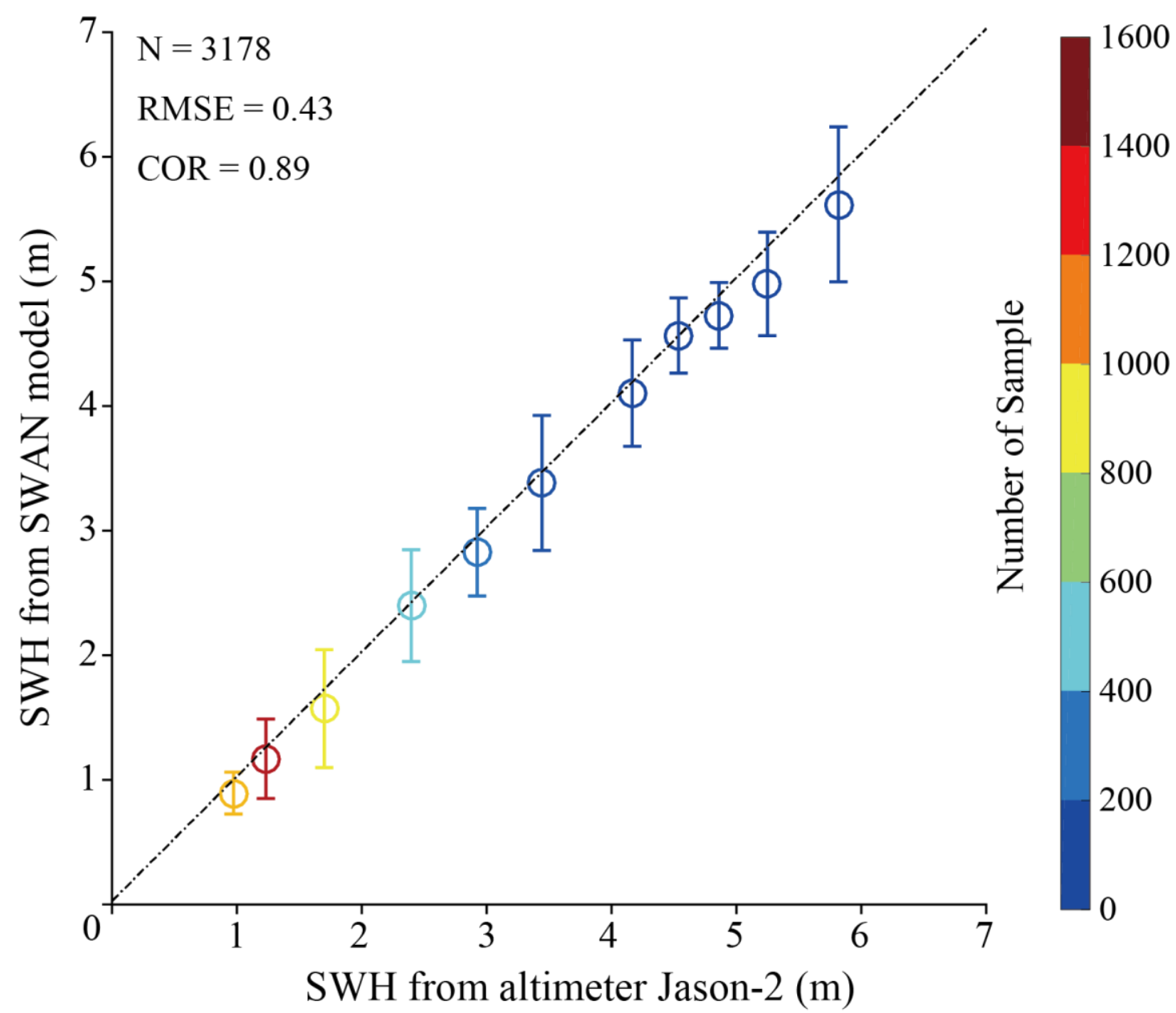

2

Fig. 6. SWAN-simulated SWHs contrasted with Jason-2 altimeter measurements 3 The bin was set to 0.3 in a range spanning 1-6 m. 


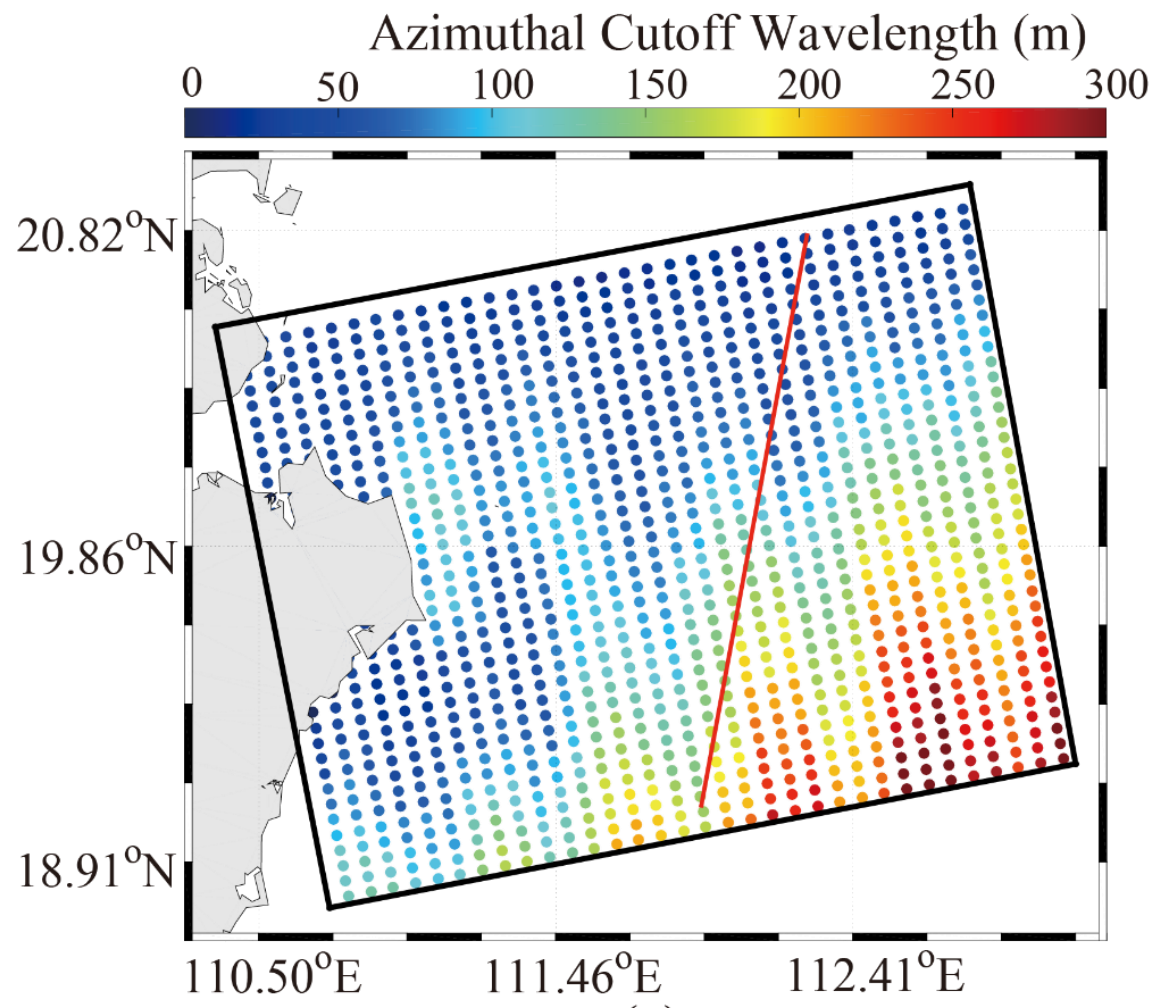

(a)

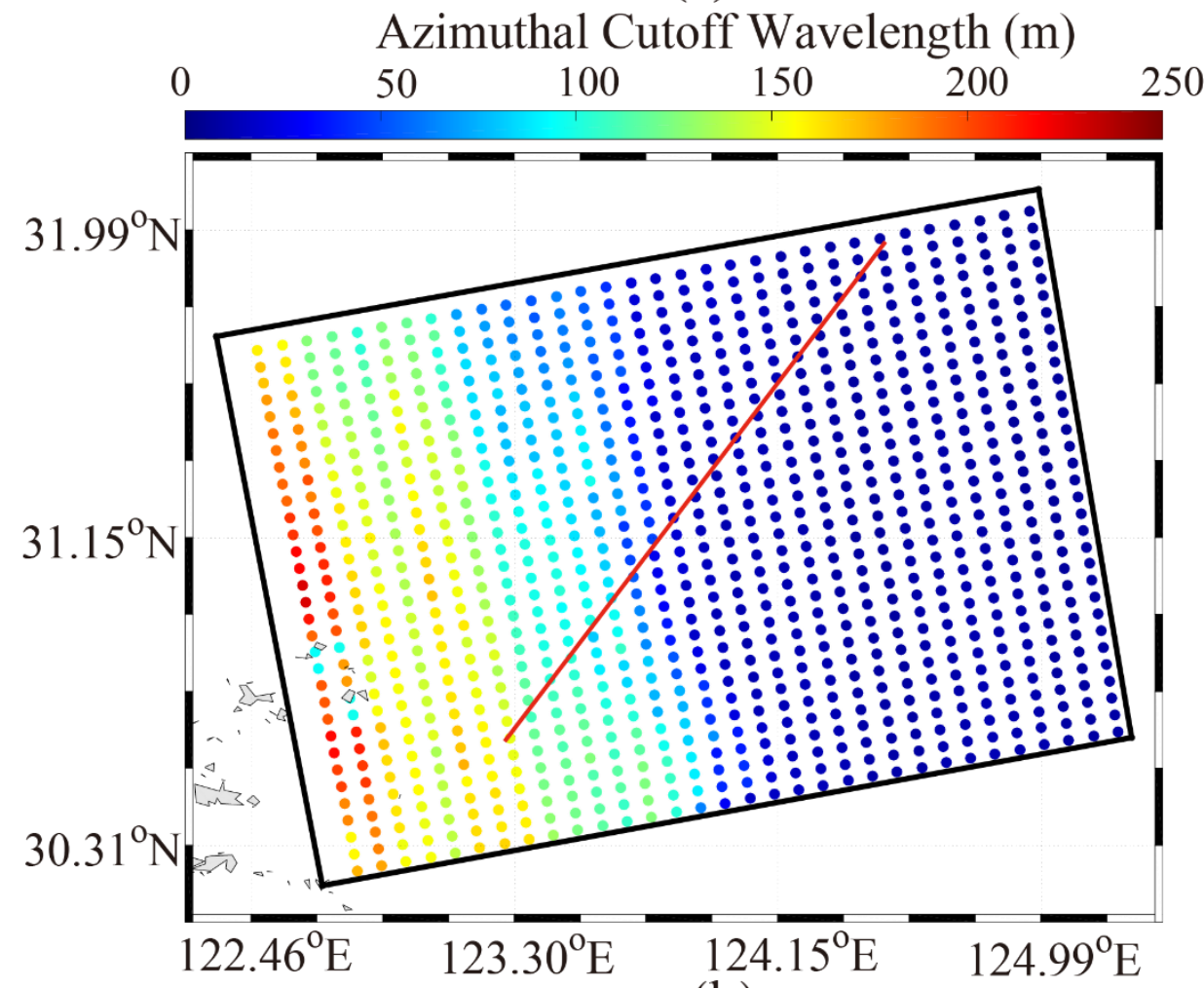

(b)

Fig. 7. Azimuthal cut-off wavelengths estimated using the simulated two-dimensional wave spectrum from the SWAN model

4 The red lines and rectangles are selected profiles across the ocean fronts for (a) the S-1 5 SAR image in the South China Sea and (b) the SAR image in the East China Sea. 

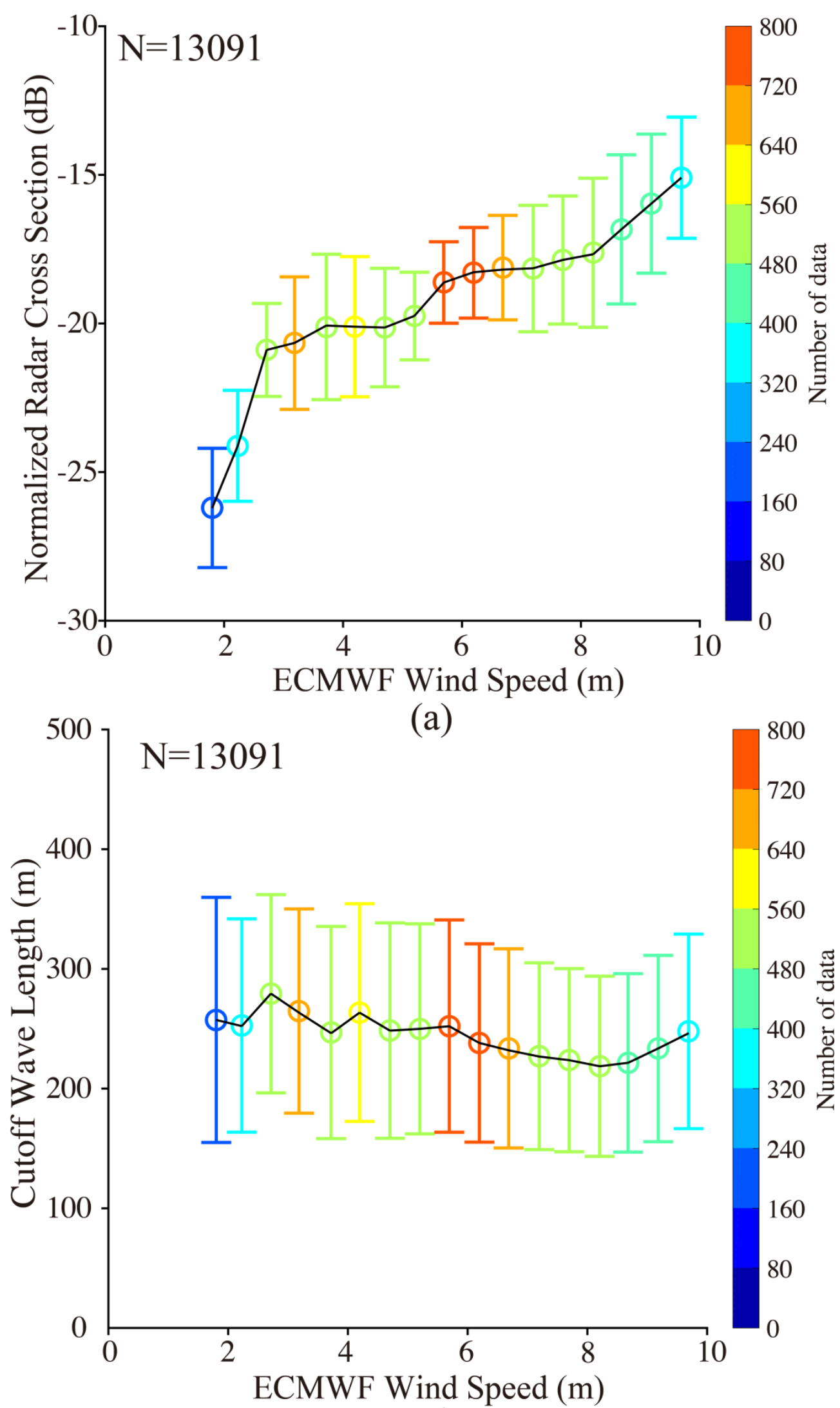

(b)

2 Fig. 8. ECMWF wind speed contrasted with: (a) SAR-measured NRCS, and (b) azimuthal cut-off wavelength 

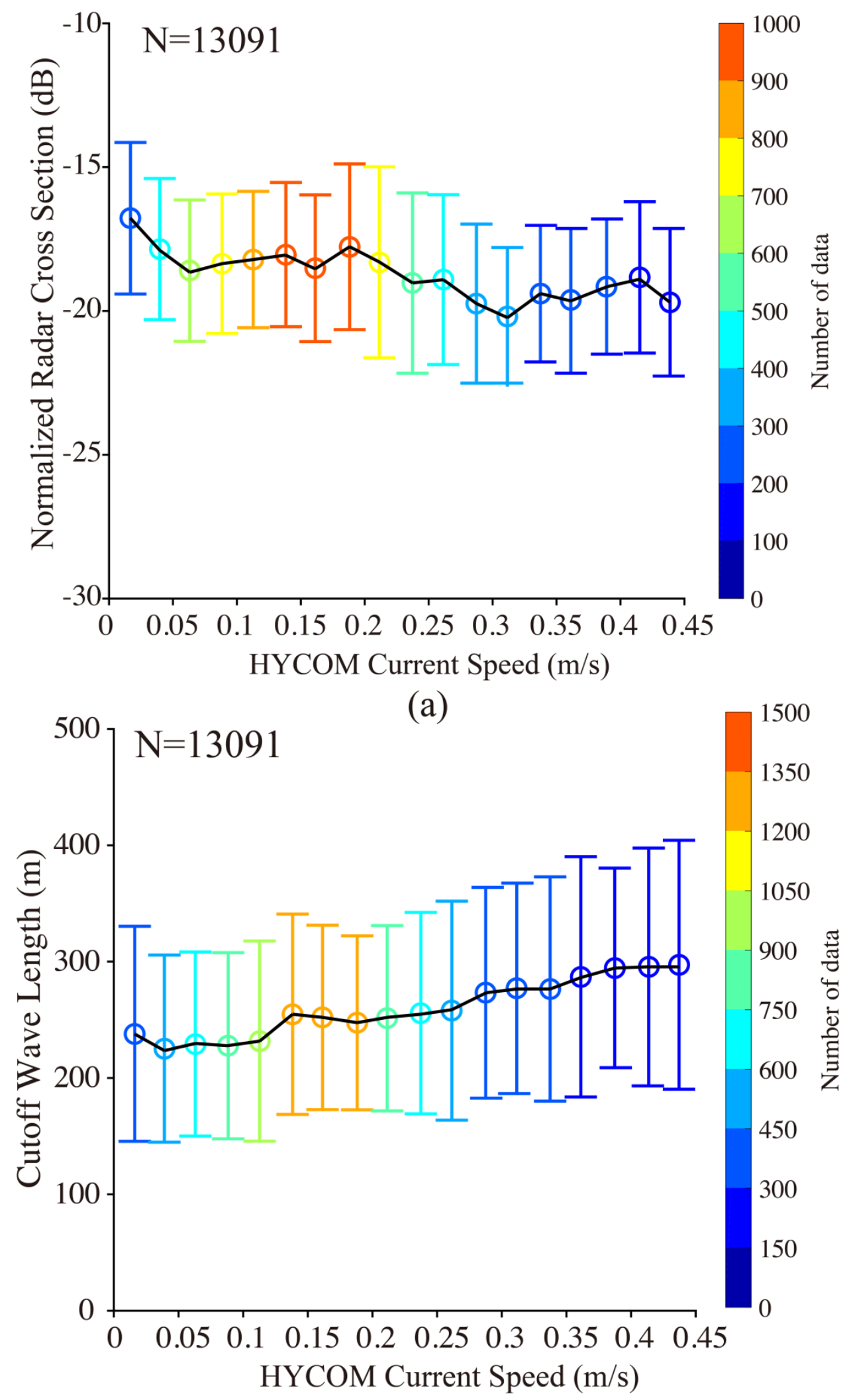

2 Fig. 9. HYCOM current speed contrasted with: (a) SAR-measured NRCS, and (b) 


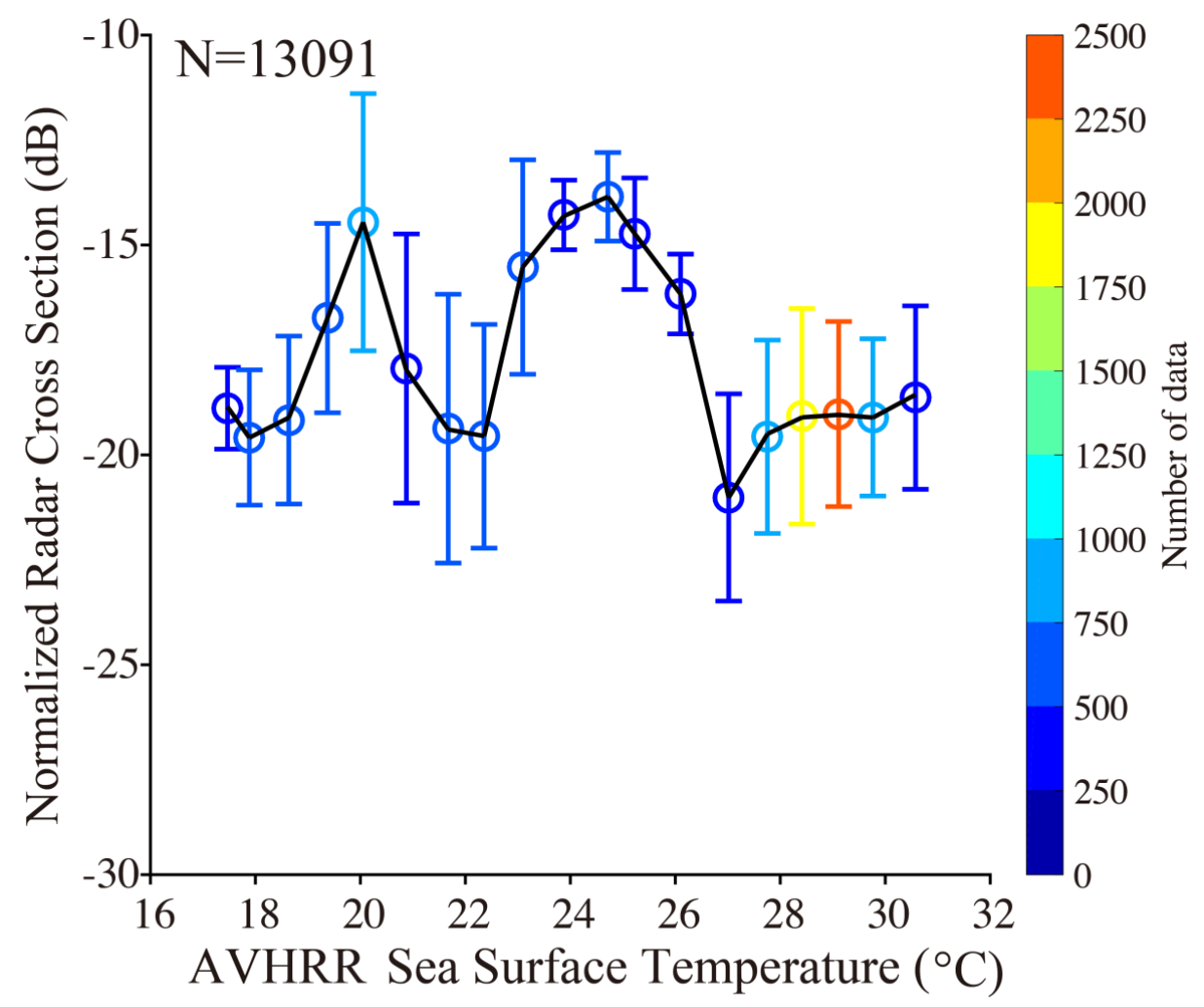

(a)

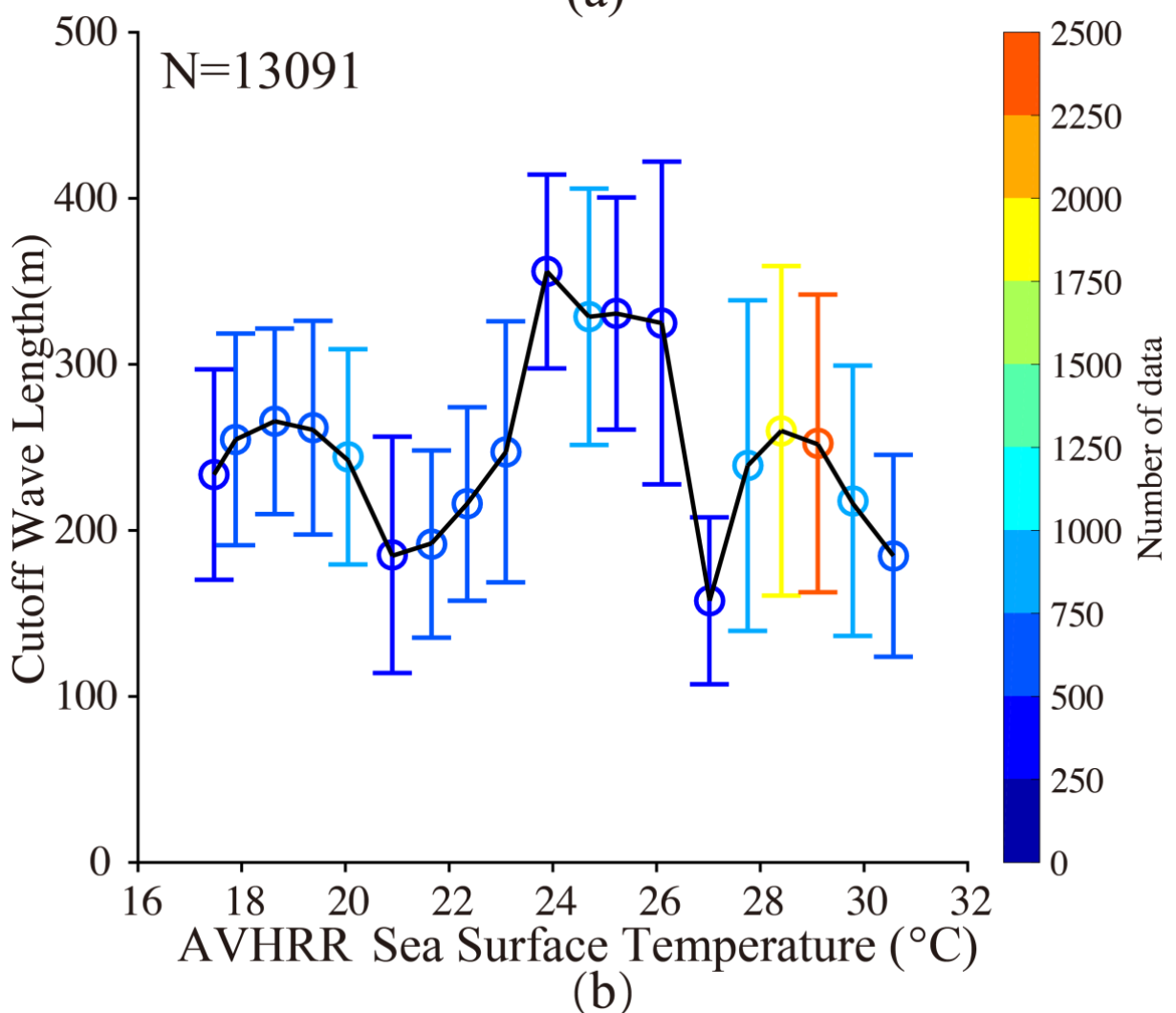

2 Fig. 10. AVHRR SST contrasted with: (a) SAR-measured NRCS, and (b) azimuthal 3 cut-off wavelength 


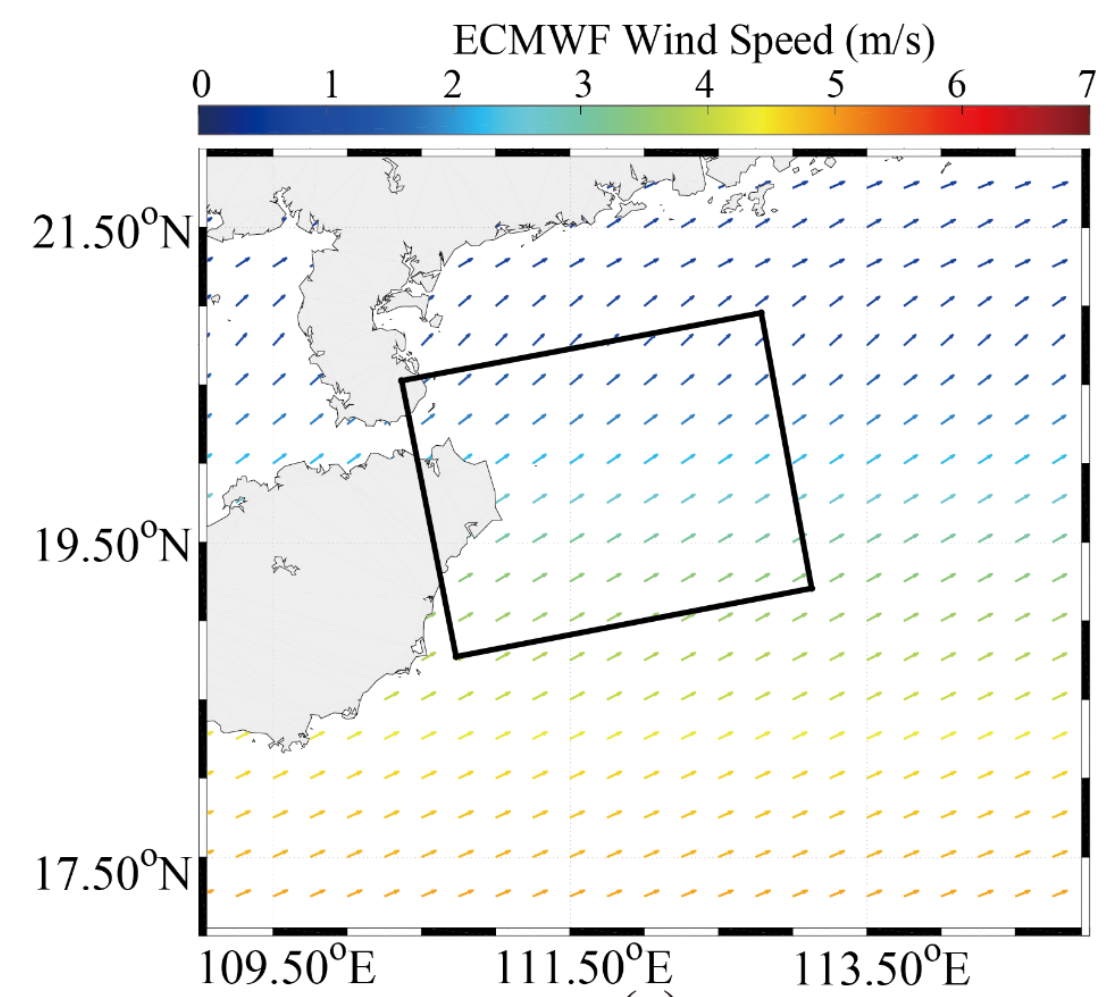

(a)

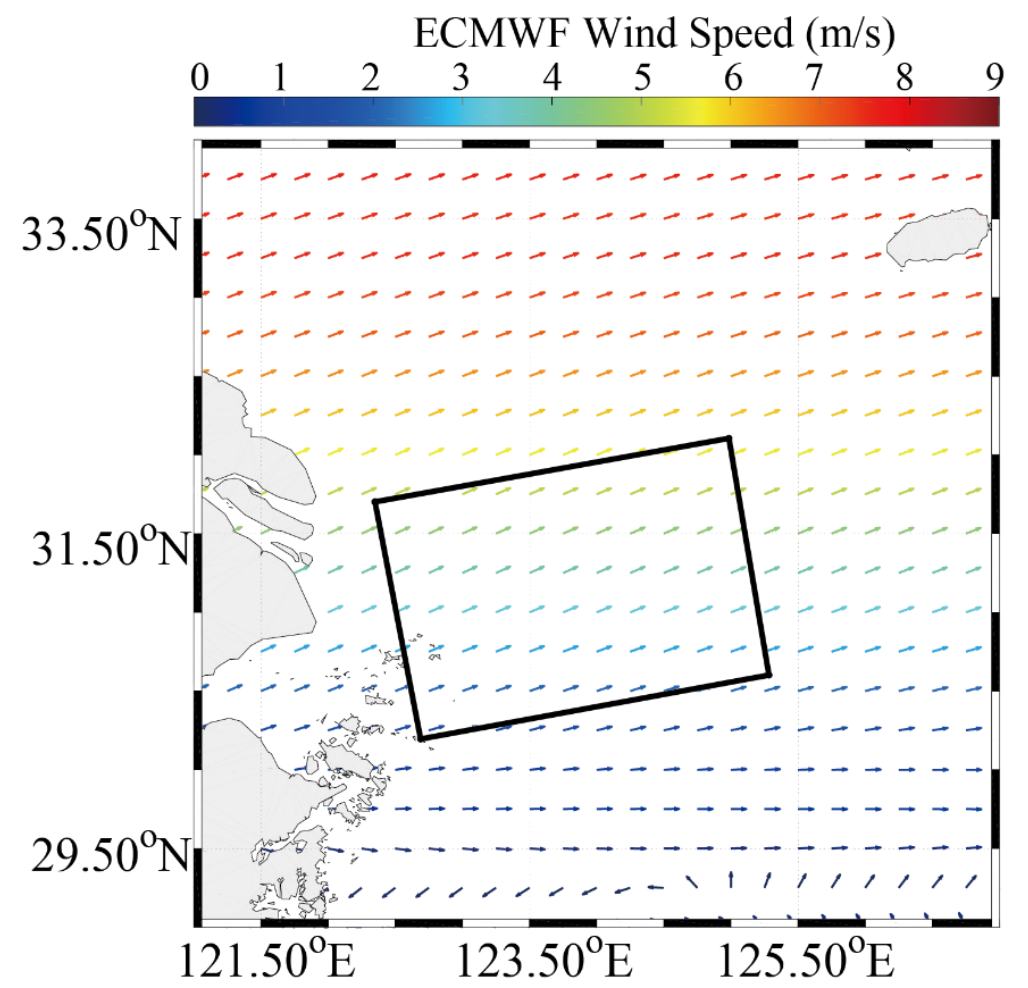

(b)

Fig. 11. ECMWF wind maps in which the black rectangles represent the spatial coverage of the two SAR images: (a) August 27, 2018 at 12:00 UTC in the South China Sea; (b) June 15, 2016 at 12:00 UTC around the Zhoushan Islands 

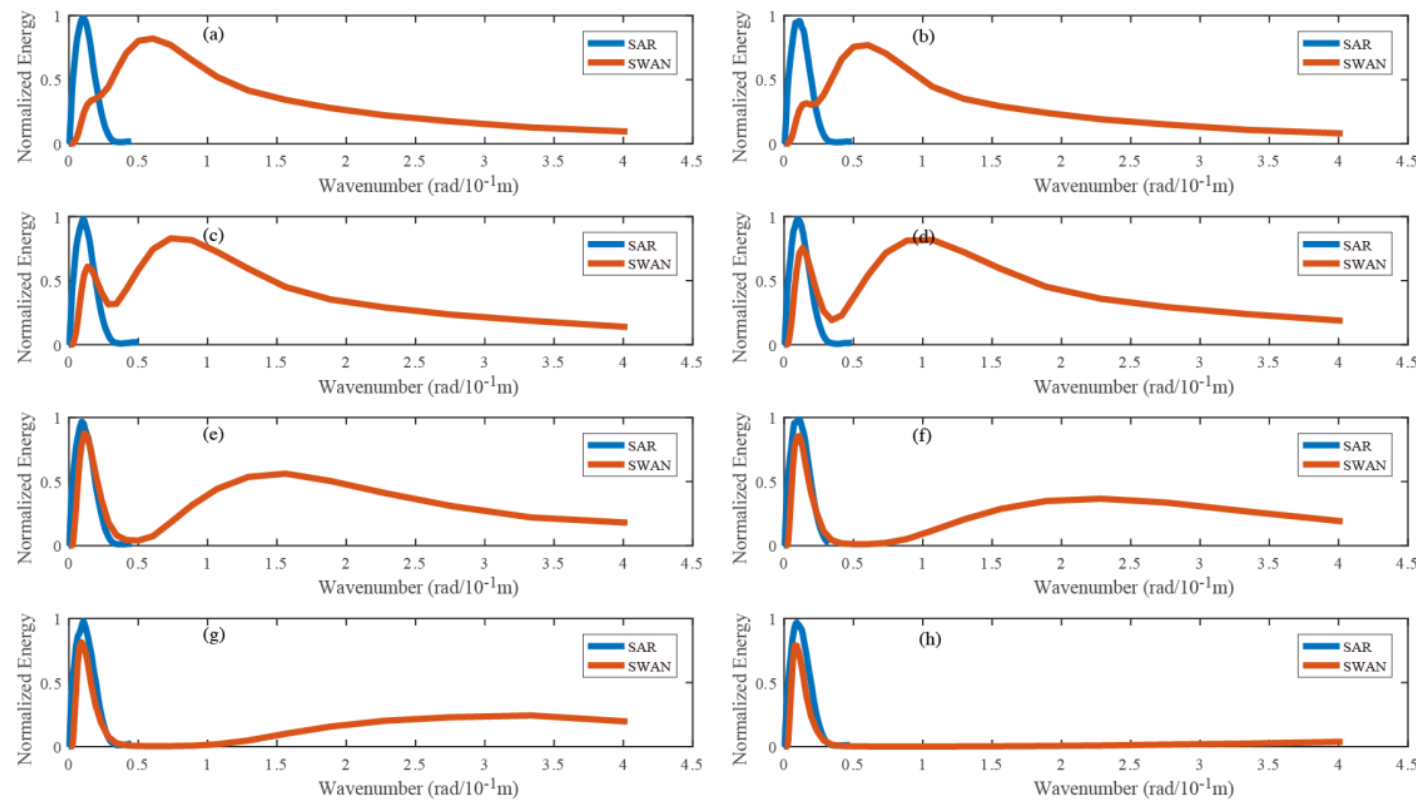

Fig. 12. Wave spectra derived from SAR images (blue curves) contrasted with the spectra simulated using the SWAN model (red curves)

The panels (a)-(n) stand represent the estimations/simulations corresponding to the markers A-H in Figure 2(a).
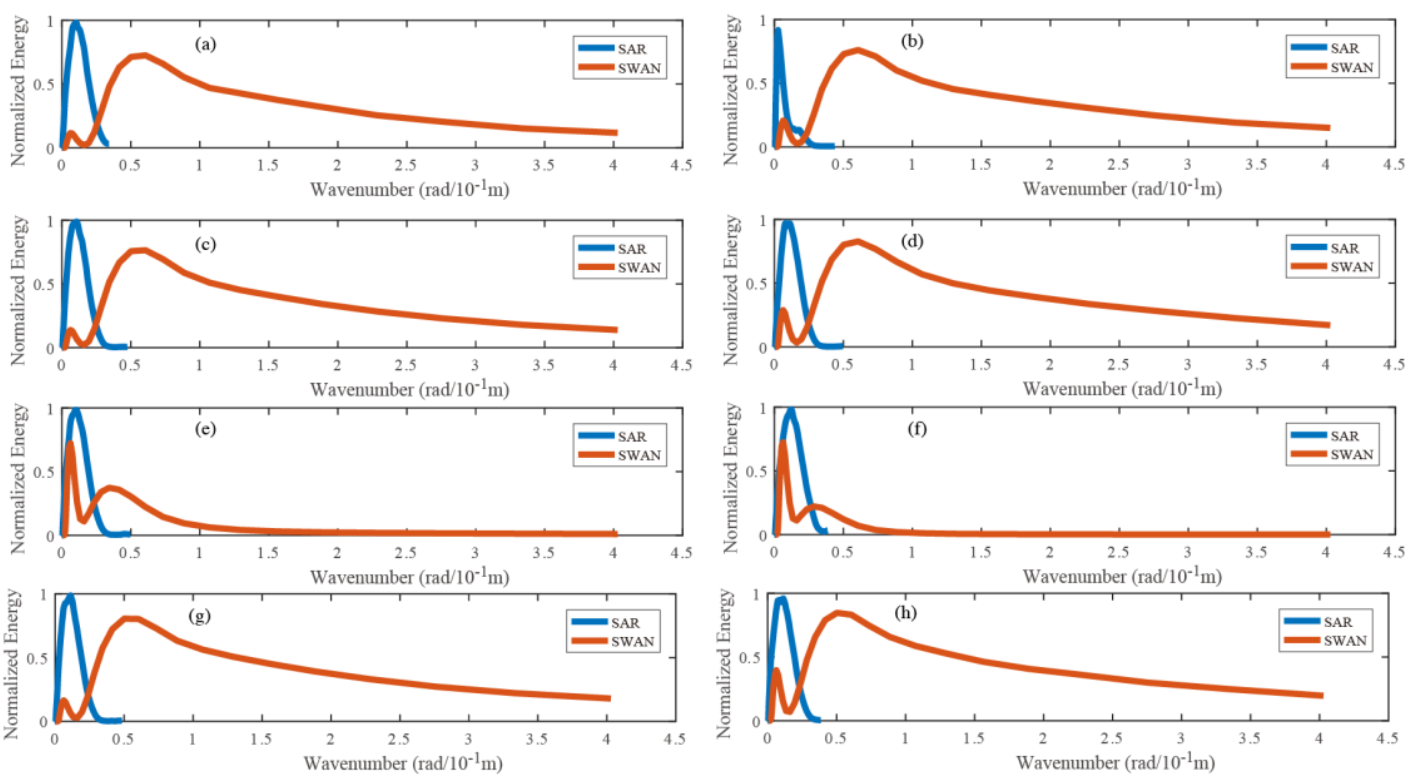

Fig. 13. Wave spectra derived from SAR images (blue curves) contrasted with the spectra simulated using the SWAN model (red curves)

The panels (a)-(n) represent the estimations/simulations corresponding to the markers A-H in Figure 2(b). 